\title{
An Exploratory Examination of Relationship Value in Inter-enterprise Cooperation
}

\author{
Wang Lan \\ Department of Management Science and Engineering \\ Business School \\ East China University of Science and Technology \\ Shanghai, China \\ wanglan535@126.com
}

\author{
Liu Gang \\ Department of Management Science and Engineering \\ Business School \\ East China University of Science and Technology \\ Shanghai, China \\ liugang@ecust.edu.cn
}

\begin{abstract}
On the basis of fairness theory, relationship marketing theory and social exchange theory, this manuscript develops a conceptual model to confirm three perceived fairness ( distributive fairness, procedural fairness and interactional fairness), as well as three kinds of relationship quality ( satisfaction, trust and commitment) which can help to study the relationship value of corporate cooperation. Questionnaires of 198 B2B companies from the automotive industry indicate that procedural fairness and interactional fairness affect the relationship value through satisfaction, while distributive fairness affects the relationship value not through satisfaction. The results also indicate that satisfaction has a significant positive effect on trust, and trust has a significant positive effect on commitment. What's more, satisfaction, trust and commitment all show a significant positive effect on relationship value.
\end{abstract}

Keywords-fairness; relationship quality ; relationship value

\section{INTRODUCTION}

In order to improve the efficiency and gain benefit, more firms are seeking to engage in co-operative long term partnerships. Wilson and Jantrania (1995) found interenterprise cooperation relationships could create value by researching the industrial market supply and demand. Relationship quality is the antecedent of relationship value, including satisfaction trust and commitment. Kumar et al. investigated how fairness moderates the relationships between auto dealers in the USA, and implicated that fairness was crucial to maintaining effective relationship quality and interenterprise cooperation performance.

Inter-enterprise cooperation relationships will be affected by various factors, such as perceived fairness which is emphasized important to maintain cooperation relationship by fair theory. If one partner fells unfair, the relationship will be destroyed or even ended. Fairness is a fundamental factor for relationship quality and value. Meanwhile, research on channel relationships indicates that fairness can help to develop and maintain channel relationships, so that most firms would rather sacrifice their own profit margins to hold mutual perceived fairness. This study takes into account three distinct types of fairness (distributive fairness, procedural fairness, and interactional fairness). Distributive fairness means that relationship partners' rewards are proportionally matched to their contributions. Procedural fairness means the processes of

Sponsored by Humanities and Social Sciences Project of the Ministry of Chinese Education (No.10YJA790112). relationship is just and transparent. Interactional fairness means partners can be can be treated with polite, respect and dignity.

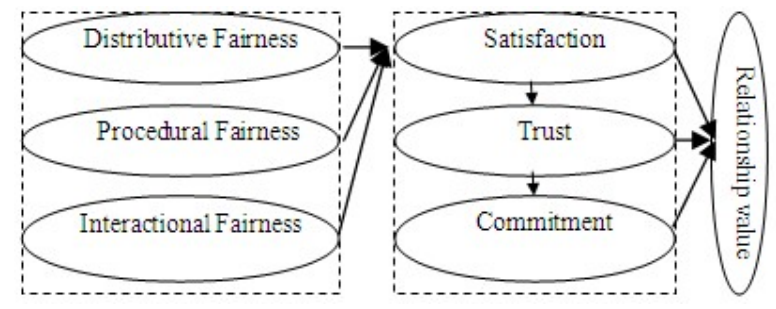

Fig. 1. A model of relationship value in inter-enterprise cooperation

Extant research exits some problems. First, although scholars adopt fairness's influences on inter-enterprise cooperation, few focus on influence paths of fairness to relationship value. Second, exploratory examination of interaction among satisfaction, trust and commitment is rare.

This research integrates the literature on social exchange theory, fairness theory and relationship marketing, at the same time referring to research on influences between fairness, relationship quality and relationship value, in order to building the conceptual framework (Fig. 1) In the proposed framework, perceived fairness and relationship quality help to shape interenterprise relationships value and explain its influence path which can addresses the gap in the extant research.

\section{THEORETICAL BACKGROUND AND HYPOTHESES}

\section{A. Fairness and satisfaction}

Satisfaction is a member's positive affective response to inter-enterprise relationships, and Solomon said satisfaction would be effected by fairness. If partners fell to be fairly treated in cooperation, they will be more satisfied, otherwise they will be negative. Distributive, procedural, and interactional fairness are proposed to affect satisfaction with the cooperation relationships.

James R et al. (2006) analysed influences of distributive justice and procedural justice on satisfaction via surveying suppliers - retailers relationships, finding that distributive justice and procedural justice are positively related to satisfaction. Procedural fairness can promote satisfaction in 
inter-enterprise relationship, because enterprises get more psychological satisfaction. Young and Soocheong (2009) discussed the effect of interactional fairness on satisfaction in the U.S. restaurant industry. They stress the mediating role of satisfaction between interactional fairness and future outcomes. Parties that are treated with politeness and respect during the cooperation processes will likely be more satisfied with the relationship.

According to relationship marketing theory, only when the expectation of enterprises is realized, is it possible to be satisfied with cooperative members. Firms carry out cooperation, with the purpose of sharing cost and interests. If enterprise fells unfair in the cooperation, he will be dissatisfied, especially when the input isn't matched to output.

H1a : Distributive fairness is positively related to satisfaction in inter-enterprise cooperation.

$\mathrm{H} 1 \mathrm{~b}$ : Procedural fairness is positively related to satisfaction in inter-enterprise cooperation.

H1c : Interactional fairness is positively related to satisfaction in inter-enterprise cooperation.

\section{B. Relationship quality: satisfaction, trust and commitment}

Through the empirical study of advertising industry cooperation relationship, Ruben et al. ( 2007 ) found satisfaction positively influenced trust, and trust positively influenced commitment. If both sides of cooperation share good team-spirit and altruism, they can well understand of each other's needs, which can help each other to achieve mutual trust and ensure to carry out close cooperation. If one partner bears another a grudge, they will be probably trapped in the prisoner's dilemma. Good emotional reaction can reduce uncertainty, and generate trust.

Morgan and Hunt ( 1994 ) insisted trust was the antecedent of commitment. Goodman and Dion viewed that market and behavior factors would influence commitment, and trust was the most important behavior factor. Trusting each other can improve the quality of the commitment, which makes cooperation be more stable. Conversely, if partners are lack of trust, one won't make a promise to another. Cooperation will become temporary short-term relationship.

$\mathrm{H} 2$ : Trust is positively related to satisfaction in interenterprise cooperation.

H3: Commitment is positively related to satisfaction in inter-enterprise cooperation.

\section{Relationship value and relationship quality}

Whittaker et al. (2007) asserted satisfaction was primary influence factor for relationship value. Satisfaction can reduce the friction and conflict of cooperation, so that both sides will be more willing to share knowledge, technology and resource with each other, which makes for consolidating cooperation.

Trust can prevent partners to engage in opportunistic behavior, as trust influence firms' perceived risk, making partners believing peers to act in their best interests.
Cooperation exits high uncertainty. On the one hand, technology risk, market risk and resource risk may result in the failure of cooperation. On the other hand, moral risk, opportunism and adverse selection may also result in the split of the relationship. Under the condition of high risk and high failure rate, partners must trust each other to keep stable relations, so as to obtain higher interest.

Commitment can help partners meet self-actualization needs, and gain more profit, because high commitment may help firms resist short- term temptations, to pursuit long-term interests. Because of increasing cost, enterprises now have turned to seek cooperation instead of previous independent operation. On the one hand, enterprises can deal with high investment. On the other hand, enterprises can also share proprietary technology and resources of each other. If one party finds another negative in the cooperation, he will inevitably seek other alternative partners under the pressure of cost and technology. But if the partners reach a common understanding of relationship commitment, enterprise will weigh the commitment cost and search cost. The main form of commitment is the investment in cooperation relationship, which can guarantee the stability of the relationship and the loyalty of partners.

H4 : Relationship value is positively related to satisfaction in inter-enterprise cooperation.

H5: Relationship value is positively related to trust in inter-enterprise cooperation.

H6 : Relationship value is positively related to satisfaction in inter-enterprise cooperation.

\section{RESEARCH METHODOLOGY}

\section{A. Sample and data collection}

The context for this study is the supply and demand relationship in auto industry. Data for this study was collected via a questionnaire in East China University of Science and Technology MBA students, who are engaged in inter-enterprise cooperation. A total of 260 questionnaires were sent, with 214 of these were returned, 198 of these deemed usable, so usable response rate nearly $76.2 \%$. 81 firms are devoted to cooperate less than three years, and the others are on the contrary.

\section{B. Measurement of variables}

To ensure content validity, all constructs were measured referring to extant research. All variables were measured using multiple item scales and scale items generated. Every fairness was measured using a 3-item scale, and satisfaction, trust ,commitment were measured separated using a 6-item, 4item, 3-item scale, while relationship value was measured using a 3-item scale.

\section{Validation and reliability of measures}

(1) Reliability analysis. Following guidelines for item editing, all measures should be reviewed prior to data collection to help ensure adequate levels of face validity. This study utilized reliability analysis via SPSS 20.0 to measure Cronbach's Alpha values. Table I shows the scales measuring 
of each factor, Alpha value ranging from 0.79 to 0.93 . Reliability measures above 0.7 are used as the common standard, suggesting our reliabilities sufficed for exploratory research.

TABLE I. RELIABILITY ANALYSIS OF VARIABLES

\begin{tabular}{|c|c|c|c|}
\hline Variables & Alpha & Variables & Alpha \\
\hline Distribution Fairness & 0.79 & Satisfaction & 0.93 \\
\hline Procedural fairness & 0.86 & Trust & 0.86 \\
\hline Interactional fairness & 0.87 & Commitment & 0.86 \\
\hline Relationship value & 0.87 & & \\
\hline
\end{tabular}

TABLE II. VALIDITY ANALYSIS OF VARIABLES

\begin{tabular}{|c|c|c|c|}
\hline $\begin{array}{c}\text { Kariables } \\
\text { Index }\end{array}$ & $\begin{array}{c}\text { Perceived } \\
\text { fairness }\end{array}$ & $\begin{array}{c}\text { Relationship } \\
\text { quality }\end{array}$ & $\begin{array}{c}\text { Relationship } \\
\text { value }\end{array}$ \\
\hline CMIN & 30.89 & 95.65 & 12.15 \\
\hline CMIN/DF & 1.40 & 1.62 & 1.74 \\
\hline GFI & 0.97 & 0.93 & 0.98 \\
\hline TLI & 0.99 & 0.98 & 0.98 \\
\hline CFI & 0.99 & 0.98 & 0.99 \\
\hline RMSEA & 0.05 & 0.06 & 0.06 \\
\hline RMR & 0.03 & 0.04 & 0.04 \\
\hline
\end{tabular}

(2) Validity analysis. Convergent validity analysis was conducted using confirmatory factor analysis. The result shows that standardize factor loading of every variable is no less than 0.55 , while the threshold is 0.4 , so convergent validity meets research demand. The minimum factor loading T-value is 6.61, greater than 2 indicating adequate value, so factor loading is statistically significant. Table II shows fit index of main variables, also indicating validity fits the bill.

\section{ANALYSIS AND RESULTS}

This study discussed mutual influences between variables and influence path of relationship value by means of Structural Equation Model. We modeled initial model on the base of conceptual framework (Fig. 1) with the help of AMOS20.0. We checked goodness-of-fit scores of the initial structural equation model to verify eight hypothesizes. Table 3 shows the outcomes of model fitting.

This study analyses basic adapter index, absolute adapter index, incremental adapter index and contracted adapter index to evaluate initial model overall goodness of fit. We can come to the under conclusions from table III and table IV.

(1) Basic adapter index. First, S.E. of all path coefficients are positive. Second, besides C.R. is 1.46 in distributive justice $\rightarrow$ satisfaction, all path coefficients C.R. are greater than indicating adequate value1.96. Third, factor loading of measured variable and measured index is between standard ranges $0.5-0.95$. All of the above indicate that basic adapter index of all model paths is workable besides distributive justice $\rightarrow$ satisfaction.

(2) Absolute adapter index. RMSEA is 0.06 , less than indicating adequate value 0.08 , GFI is 0.83 , greater than indicating adequate value 0.8 , both workable.

(3) Incremental adapter index. NFI is 0.90 , and IFI is 0.95 , both greater than indicating adequate value 0.8 , meeting standard.

(4) Contracted adapter index. CMIN/DF is 1.72 , less than indicating adequate value 2.5 .

All of above indicate model matching with actual data. Meanwhile, we can find from table 3 that $p$-value is less than 0.05 of every path besides distributive justice $\rightarrow$ satisfaction. Pvalue is notable when $p \leq .05$. So, only one path distributive justice $\rightarrow$ satisfactionis invalid, the others are practical, meaning that only $\mathrm{H} 1 \mathrm{a}$ is failing, other hypothesizes are effectual.

\section{CONCLUSIONS}

Procedural justice and interactional justice affect relationship value through satisfaction. Satisfaction is the most direct and the most rapid response to the cooperation process, and is obvious in the short term. Therefore, if the enterprises want to obtain the success in cooperation, they must please others in a short time, which can hardly realize without the help of interaction fairness and procedural justice. Although fairness is a kind of psychological activities, from the management point of view, enterprises can control cooperation process, in which they can design reasonable system and do well with the staff communication, in order to cultivate organizational justice in imperceptible.

Satisfaction is the foundation to relationship value, because satisfaction has a significant positive effect on trust, and trust has a significant positive effect on commitment. If one partner fails to meet the demand and satisfactory degree of another partner, there is to be a negative effect on trust in each other. Low levels of trust can't return for each other's promise, therefore, satisfaction is the basic factor in cooperation. Interenterprise cooperation is a continuous process, which makes future actions of enterprises to be affected by the past behavior. Satisfaction can't fully represent the before relationship behavior, but it is the most important and the most direct reflect on the cooperation before.

TABLE III. FIT STATISTICS FOR THE MEASUREMENT MODEL OF THE HYPOTHESIZED DIMENSIONS

\begin{tabular}{|c|c|c|c|c|c|c|c|c|}
\hline \multicolumn{4}{|c|}{ Paths } & S.E. & C.R. & $\mathbf{P}$ & Estimates & Hypothesis \\
\hline H1a & satisfaction & $<---$ & procedural fairness & 0.037 & 4.796 & $* * *$ & 0.306 & Unsupported \\
\hline $\mathrm{H} 1 \mathrm{~b}$ & satisfaction & $\begin{array}{l}<-- \\
\end{array}$ & Interactional fairness & 0.082 & 3.869 & $* * *$ & 0.464 & Supported \\
\hline $\mathrm{H} 1 \mathrm{c}$ & satisfaction & $<---$ & Distributive fairness & 0.049 & 1.463 & 0.144 & 0.101 & Supported \\
\hline $\mathrm{H} 2$ & trust & $\begin{array}{l}<-- \\
<-\end{array}$ & satisfaction & 0.170 & 11.278 & $* * *$ & 1.069 & Supported \\
\hline $\mathrm{H} 3$ & commitment & $<---$ & trust & 0.080 & 13.378 & $* * *$ & 1.044 & Supported \\
\hline $\mathrm{H} 4$ & relationship value & $<---$ & commitment & 0.092 & 2.754 & 0.006 & 0.338 & Supported \\
\hline H5 & relationship value & $<---$ & satisfaction & 0.099 & 2.168 & 0.030 & 0.154 & Supported \\
\hline H6 & relationship value & $<---$ & trust & 0.100 & 4.025 & $* * *$ & 0.517 & Supported \\
\hline
\end{tabular}


TABLE IV. FitTING INDEX ANALYSIS

\begin{tabular}{|c|c|c|c|}
\hline Fitting index & & Fitting index & \\
\hline DF & 335 & TLI & 0.95 \\
\hline CMIN/DF & 1.72 & GFI: & 0.83 \\
\hline RMSEA & 0.06 & IFI & 0.95 \\
\hline NFI & 0.90 & CFI & 0.96 \\
\hline
\end{tabular}

Meanwhile, satisfaction trust and commitment all have a significant positive effect on relationship value. We can deduce that the direct effect of satisfaction on relationship value is 0.15 , and the indirect effect is 0.38 . So the total effect of satisfaction on relationship value is 0.79 . Also, we can figure out the direct effect of trust on relationship value, which is 0.52 , while the indirect effect is 0.35 . So the total effect of trust on relationship value is 0.87 . At last, we can deduce that the direct effect of communication on relationship value is 0.34 , and the indirect effect is 0.00 . So the total effect of satisfaction on relationship value is 0.34 . In conclusion, satisfaction has the most positive effect on relationship value, and commitment has the weakest positive effect on relationship value. The influence of trust is between satisfaction and commitment.

Certain limitations of this study should be noted. First, the effect of distribution fairness on relationship value is worthy of further investigation. According to the exiting literature, we know that distribution fairness does have indirect effect on relationship value, but we don't know the specific path. Second, the sample range should be extended. Data of this study is mainly from southern firms in China, and collecting more data from all over the world maybe draw better results.

Further research could focus on the influence paths of relationship value in different relationship types, discussing whether differences exist in various kinds of relationships. What's more, how distribution fairness acts on relationship value is a second key research content.

\section{REFERENCES}

[1] Wilson, David T. and Swati Jantrania. Understanding the Value of a Relationship . Asia-Australia Marketing Journal, 19952 (1): pp. 55-66.

[2] Kumar NLK, Scheer. J-BEM and Steenkamp. The Effects of Supplier Fairness on Vulnerable Resellera. Journal of Marketing Research, vol.32(1),1995, pp. 54-65.

[3] Solomon. M.R., Surprenant. C., Czepiel, J.A. and Gutman. E.G. A role theory erspective on dyadic interactions: the service encounter. Journal of Marketing vol.49, 1985, pp. 99-111.

[4] Ramaswami SN, Singh J. Antecedents and consequences of merit pay fairness for industrial sales people. Journal of Marketing, vol. 67, October 2003, pp.46-66.

[5] James R. Brown. Anthony T. Cobb. And Robert F. Lusch. The roles played by interorganizational contracts and justice in marketing channel relationship. Journal of Business Research, vol.59, 2006, pp. $166-175$.

[6] Yi Liu, Ying Huang, Yadong Luo and Yang Zhao. How does justice matter in achieving buyer-supplier relationship performance?. Journal of Operations Management, vol. 30, 2012, pp. 355-367.

[7] Young Namkung and SooCheong (Shawn) Jang. The effects of interactional fairness on satisfaction and behavioral intentions: Mature versus non-mature customers. International Journal of Hospitality Management, vol.28, 2009, pp. 397-405.

[8] Ruben Chumpitaz Caceres and Nicholas G. Paparoidamis. Emerald Article: Service quality, relationship satisfaction, trust, commitment and business-to-business loyalty. European Journal of Marketing, vol. 41, 2007, pp.836-867.

[9] Morgan, R.M. and Hunt, S.D. The commitment-trust theory of relationship marketing. Journal of Marketing, vol. 58, no.3, 1994, pp. 20-38.

[10] Goodman L E and Dion P A. The determinants of commitment in the distributor-manufacturer relationship. Industrial Marketing Management, vol.30 ( 3) , 2001, pp. 287-300.

[11] Graham Whittaker, Lesley Ledden and Stavros P. Kalafatis. Emerald Article: A re-examination of the relationship between value, satisfaction and intention in business service. Journal of Services Marketing, vol. 21, no.5, 2007, pp. 345-357.

[12] Spekman, R. E. and Davis, E. W. Risky business: Expanding the discussion on risk and the extended enterprise. International Journal of Physical Distribution \& Logistics Management, vol.34(5), 2004, pp. 414-433.

[13] Anderson, E. and Weitz, B.A. The use of pledges to build and sustain commitment in distribution channels. Journal of Marketing Research, vol. 29 (1), 1992, pp. 18-34. 